\title{
Experience on Implementing a Project for Educating Students on Runaway Reaction Dynamics
}

\author{
A. Stammitti-Scarpone ${ }^{l}$; E. Passeport ${ }^{1,2 *}$; G. Evans ${ }^{l}$; R. Mahadevan ${ }^{l}$ \\ ${ }^{1}$ Department of Chemical Engineering \& Applied Chemistry, University of Toronto, Canada \\ ${ }^{2}$ Department of Civil Engineering, University of Toronto, Canada \\ elodie.passeport@utoronto.ca
}

\begin{abstract}
To build awareness in second-year chemical engineering undergraduate students on runaway reaction dynamics and associated safety concerns, and to help students better identify crossovers between two different courses, a combined team project between the Heat and Mass Transfer and Applied Differential Equations courses at the University of Toronto has been implemented. To evaluate the effectiveness of this combined project on students learning, a survey was conducted around four different perspectives: (A) Contribution to learning, (B) Motivation and awareness, (C) Project structure and support, and (D) Personal experience and skills development. The results of the survey demonstrated that the project was effective at bringing awareness about safety issues and the role of students as future professional engineers. It helped them better learn the concepts seen in both courses and develop their team skills. A critical analysis of these results helped to provide guidance for improvement in future years are discussed.
\end{abstract}

Keywords: Thermal runaway reaction, dynamic heat transfer, reactive process dynamics, multicourse project based learning, student experience survey.

\section{INTRODUCTION}

Thermal runaway in batch reactions is an important and frequent cause of catastrophic reactive chemical incidents. Over 58 accidents were reported in the United States between 1980 and 2001 [1], and 13 accidents occurred in Canada between 1940 and 1990 [2]. Approximately $35 \%$ of these accidents resulted in explosion or fire, and deaths. The major root causes of these accidents are: insufficient understanding of the process chemistry, kinetics and associated hazards; poor design of the cooling and emergency gas relief systems; inadequate control and safety systems; inadequate operating procedures, and insufficient training.
As professional engineers, our duty to the public is paramount [3]. Therefore, educating undergraduate students on chemical process safety is fundamental for preventing accidents [4], in particular to help students learn how to identify process hazards [5]. Despite an increasing interest on incorporating safety into undergraduate engineering programs, many schools treat it as a separate topic, and sometimes with insufficient hands-on exposure. Furthermore, it is also well known that courses often appear disconnected from each other, resulting in deficiencies in the capacity of the students to integrate and contextualize multiple concepts to assess a complex problem $[5,6]$.

Project-based learning $(\mathrm{PjBL})$ is an interactive studentcentered learning strategy that has proven effective in providing realistic context to the students, helping them to integrate knowledge from lectures, and developing teamwork and communication skills [7-11]. In addition, a multicourse project offers the advantage of integrating different concepts under the same context [12]. Therefore, we implemented a combined team term-project between the Heat and Mass Transfer and Applied Differential Equations courses to build awareness in second-year chemical engineering undergraduate students at University of Toronto. This combined project covered several safety-related topics such as process safety integrated with runaway reaction dynamics and the design of reactor cooling and pressure relief systems. The T2 Labs accident has been selected as the framework for the project since it has been widely studied and a mathematical model of this process has been reported $[4,13]$. The main learning objectives, listed in Table 1, are divided into three categories, namely course integration, process safety awareness and leadership objectives. To investigate the effectiveness of this combined project on reaching these learning objectives, a survey was developed to assess the learning experience and feedback from the students around four different perspectives (see Appendix). 


\section{PROJECT DESCRIPTION}

The project required the students to work in teams of 5 to 6 people to conduct heat transfer- and applied differential equations-related calculations in a series of scenarios under transient and steady state conditions. The goal was to assess the performance of the reactor's cooling and pressure relief systems, and to answer series of reflection questions regarding the errors and malpractices identified in the accident and the duties of a chemical engineer. The project was assigned $10 \%$ of the total mark for each of the courses. It was divided into mid and final report deliverables, with a $25 \% / 75 \%$ grade distribution. The questions asked in each report were aligned to the concepts taught in each course by the respective due dates. Figure 1 shows a schematic of the reactor vessel geometry presented to the students based on the $\mathrm{T} 2$ labs reactor.

\subsection{Mid report}

In the mid report, the main goal was to write the dynamic energy balance of the reactor assuming constant values for the convection coefficients within the reacting fluid, the steam jacket, and the surroundings. In addition, a simplified exothermic reaction kinetics was provided as shown in Eq. (1). The purpose was to allow the students to derive the analytical solution for the temperature profile of the reaction under different cooling jacket conditions, and show the effect of the secondary exothermic reaction on temperature and heat generated. Equation 2 is an example of the energy balance for the jacketed reactor in the form of an ordinary differential equation (ODE). To obtain the heat losses terms, the students were asked to assume that the concept of thermal resistances was applicable. The validity of this assumption was discussed.

$$
\dot{\mathrm{Q}}_{\mathrm{GEN}}=\mathrm{V}_{\mathrm{T}} \cdot\left(\mathrm{q}_{\mathrm{V} 1}+\mathrm{a} \cdot \mathrm{T}_{\mathrm{i}}\right)
$$

\section{Where:}

$\dot{\mathrm{Q}}_{\mathrm{GEN}}$ : total heat generation in the reactor $(\mathrm{W})$

$\mathrm{V}_{\mathrm{T}}$ : reactor volume $\left(6 \mathrm{~m}^{3}\right)$

$\mathrm{q}_{\mathrm{V} 1}$ : heat generation of first reaction $\left(6000 \mathrm{~W} / \mathrm{m}^{3}\right)$

a: heat generation coefficient of secondary reaction. $\mathrm{a}=36,000 \mathrm{~W} / \mathrm{K} \cdot \mathrm{m}^{3}$ if $\mathrm{T}_{\mathrm{i}} \geq 471.9 \mathrm{~K}, 0$ otherwise.

$\mathrm{T}_{\mathrm{i}}$ : reactor fluid temperature $(\mathrm{K})$.

$$
\mathrm{V}_{\mathrm{T}} \rho_{\mathrm{R}} \mathrm{Cp}_{\mathrm{R}} \frac{\mathrm{dT}_{\mathrm{i}}}{\mathrm{dt}}=\dot{\mathrm{Q}}_{\mathrm{GEN}}-\dot{\mathrm{Q}}_{\mathrm{eB}}-\dot{\mathrm{Q}}_{\mathrm{eW}}-\dot{\mathrm{Q}}_{\mathrm{RJ}}
$$

Where:

$\rho_{\mathrm{R}}$ : density of reacting mixture $\left(937 \mathrm{~kg} / \mathrm{m}^{3}\right)$

$\mathrm{Cp}_{\mathrm{R}}$ : specific heat of reacting mixture $(2.015 \mathrm{~kJ} / \mathrm{kg} \cdot \mathrm{K})$
$\dot{\mathrm{Q}}_{\mathrm{cB}}$ : heat loss from the bottom of reactor $(\mathrm{W})$

$\dot{\mathrm{Q}}_{\mathrm{eW}}$ : heat loss from the upper unjacketed wall (W)

$\dot{\mathrm{Q}}_{\mathrm{RJ}}$ : heat transferred from the reacting fluid to the jacket fluid (boiling water) (W)

The students were asked to analytically solve Eq. (2) and generate series of plots in MATLAB for different values of the heat transfer convection coefficients.

Table 1. Main learning objectives

Course integration learning objectives:

- Conduct an energy balance around the reactor.

- Write and analytically solve the ordinary differential equation (ODE) that governs heat transfer from inside of the reactor to the surroundings.

- Apply the concept of thermal resistances and use it to calculate the temperatures of the reactor walls.

- Select and evaluate the appropriate convective heat transfer correlations for each geometry and flow condition.

- Determine the required cooling water flowrates and size of the cooling coil.

- Write a code for an ODE system in MATLAB and solve it using the ODE Solver tool.

- Interpret plots showing the process variable profiles as a function of time for all scenarios.

- Assess and analyze the effect of cooling failure and pressure relief set points.

- Document the process, assumptions and choices made in designing the equipment.

Process safety awareness learning objectives:

- Identify runaway reaction hazards.

- Identify errors and malpractices in the different stages of an engineering project.

- Reflect on the duties of an engineer.

- Suggest recommendations to avoid similar accidents.

Leadership-related learning objectives:

- Identify the preferred style of teammates and describe how these styles contribute to a team.

- Identify organizational-, relational-, and communication-related behaviours and describe how these contribute to a team.

- Explain the roles of trust and conflict in effective teamwork.

- Identify and apply tools and techniques to make an engineering team more effective.

- Work and keep regular deadlines and learn how to organize work.

In addition, the students were asked to study the T2 Labs accident report [12] to identify and list ten (10) 
errors, omissions or malpractices that occurred during the T2 Labs project development and indicate in which stage each of these occurred, e.g.: conceptualization and research; scale-up design and construction; process operation. They were also asked to compare this event to another similar accident of their choice.

\subsection{Final report}

The final report consisted of four sections. In the first section, the complete design of the cooling water requirements under steady state conditions was considered. The students were requested to perform the energy balances for the reacting fluid and the cooling water. Here, the students had to select from a handout the appropriate convection coefficient correlations for each of the surfaces. The handout included convection coefficient correlations for jacketed and coiled process vessels, which were not available in the class textbook [14].

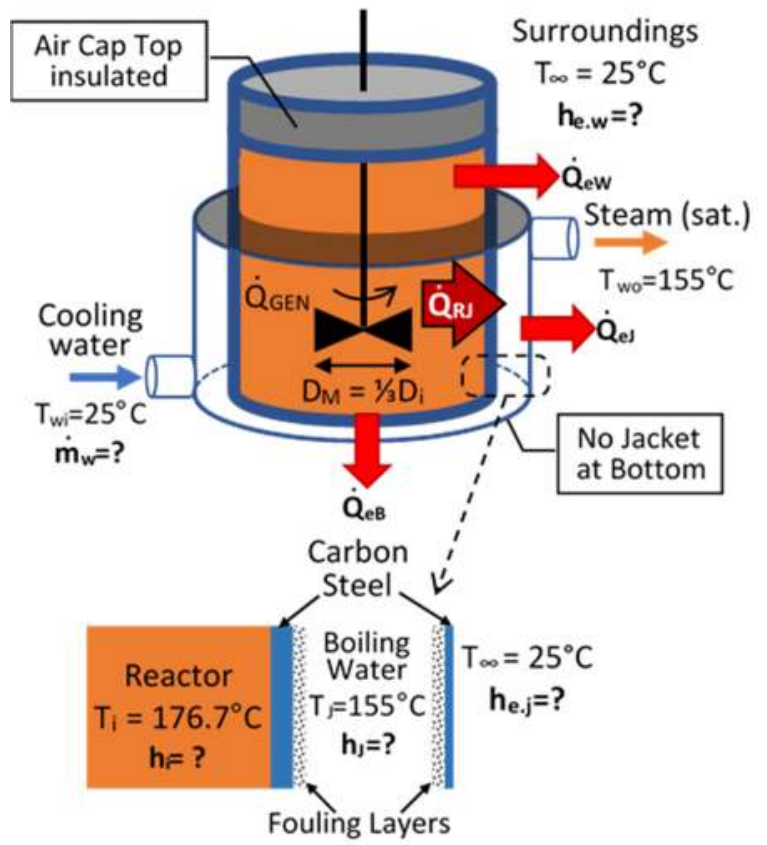

Fig. 1. Batch reactor vessel schematics in steady state

The second part of the report consisted in conducting design calculations for an emergency cooling coil, for the case of a complete cooling jacket failure, as shown in Fig. 2. The objectives were to calculate the required water flowrate and the coil length to cool down the reactor from 180 to $160{ }^{\circ} \mathrm{C}$ in 5 minutes, considering the simplified kinetics provided in Eq. (1). Given the complexity of this process, the project was designed to use a simplified approach. The students were encouraged to use Eq. (3) to estimate an average heat transfer rate from which they could estimate the required water flow rate. They were asked to use the concept of thermal resistances to calculate the coil length. Finally, to estimate the cooling coil overall heat transfer coefficient, the students were allowed to use Eq. (4) as a simplification. They were informed of the limitations of this equation, which is only valid for a temperature difference between inlet and outlet of the cooling medium lower than $10{ }^{\circ} \mathrm{C}$, and no heat generation within the system [14].

$$
\dot{\mathrm{Q}}_{\mathrm{REMOVE}}=\dot{\mathrm{Q}}_{\mathrm{GEN}}+\frac{\mathrm{V}_{\mathrm{T}} \rho_{\mathrm{R}} \mathrm{Cp}_{\mathrm{R}}\left(\mathrm{T}_{\mathrm{ini}}-\mathrm{T}_{\text {final }}\right)}{\Delta \mathrm{t}_{\text {cooling }}}
$$

Where:

$\dot{\mathrm{Q}}_{\text {REMOVE }}$ : Estimate of total heat rate to remove (W)

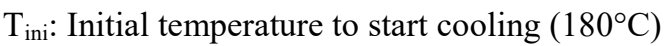

$\mathrm{T}_{\text {final }}$ : Final temperature $\left(160^{\circ} \mathrm{C}\right)$

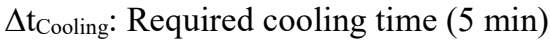

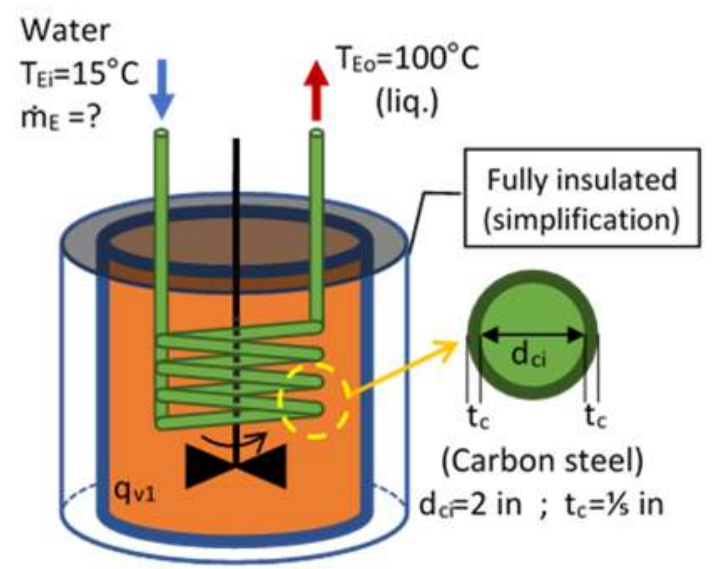

Fig. 2. Emergency cooling coil design schematics

$$
\ln \left(\frac{\mathrm{T}_{\text {final }}-\mathrm{T}_{\text {Cooling }}^{\mathrm{AVG}}}{\mathrm{T}_{\text {ini }}-\mathrm{T}_{\text {Cooling }}^{\mathrm{AVG}}}\right)=-\frac{\mathrm{UA}_{\mathrm{E}}}{\mathrm{V}_{\mathrm{T}} \rho_{\mathrm{R}} \mathrm{Cp}_{\mathrm{R}}} \Delta \mathrm{t}_{\text {Cooling }}
$$

Where:

$\mathrm{T}_{\text {Cooling }}^{\mathrm{AVG}}$ : Average cooling water temperature $\left({ }^{\circ} \mathrm{C}\right)$

$\mathrm{UA}_{\mathrm{E}}$ : Overall heat transfer coefficient of the cooling coil $(\mathrm{W} / \mathrm{K})$

In the third section of the final report, the students were provided with an ODE model developed by Wiley et al. [4]. This model incorporates the complete reaction kinetics, energy balance, and pressure profile for a lab scale reactor simulation of the $\mathrm{T} 2$ Labs process. This model also accounts for the jacket cooling system and the rupture disk used for pressure relief. The students were asked to write a MATLAB code using this ODE system to assess five different scenarios. The first four scenarios consisted of parametric studies of the effects of various heat removal rates from the jacket and rupture disk settings on the reactor performance. The students had to 
generate a series of comparative plots of temperature, pressure, and concentrations of the reagents, and provide a critical analysis of these plots in terms of design choices and safety implications. The last scenario focused on the emergency cooling coil in the case of a complete failure of the cooling jacket, modeled as an adiabatic condition. Here, the students were asked to estimate the overall heat transfer coefficient of the cooling coil to achieve the cooling effect specified in the second section of the report and compare it to the previously obtained value.

In the last section of the report, a list of reflection questions was presented to the students regarding their responsibility as professional engineers. The reflection questions are listed in Table 2. They were asked to review the code of ethics and the "Duty to report" document of Professional Engineers of Ontario (PEO) [15] to justify their answers.

Table 2. Reflection questions

- What is your main duty as an engineer?

- What would you recommend to the plant manager to prevent similar accidents from occurring?

List at least three (3) actions to take.

\section{METHODOLOGY}

To evaluate the effectiveness of this combined project on student learning towards the defined learning objectives, we developed a survey based on similar PjBL approaches [6-12]. The survey is divided into four sections as follows:

- Contribution to learning

- Motivation and awareness

- $\quad$ Project structure and support

- Personal experience and skills development

The four sections contained 21 questions that the students had to answer using 5-point Likert scale. An additional Not Applicable (N/A) option was also included for the case of a student being enrolled in only one of the two courses. A space at the end was available for the students to provide additional comments and insights. The full survey questionnaire is presented in the Appendix.

The survey was conducted at the end of the course term on a voluntarily and anonymous basis using the Google Forms tool. A consent letter was circulated in advance to inform the students about the purpose of the study. The course enrollment during the Winter 2017 term was 115 students with above $92 \%$ overlapping between the two courses. A total of 79 students responded to the survey, representing $69 \%$ of the population.

\section{RESULTS AND DISCUSSION}

The results of the 21 questions are summarized in Fig. 3 . The survey revealed that a large portion of the students, $67 \%$, enjoyed the project (accounting for those who "agreed" and "strongly agreed" to the statement in Question 16), especially because it was linked to an "actual problem that [they] may encounter" during their professional life.

\subsection{Contribution to learning}

The majority of the students agreed or strongly agreed that the combined project allowed them to practice the concepts of heat transfer $(85 \%)$ and applied differential equations $(67 \%)$, and relate the two courses better $(75 \%)$.

A student commented that this combined project "[r]eally helped teach concepts from both courses in a more applied way which greatly aided in [his/her] ability to learn". However, others commented that the "correlation between [the] two courses [could] be stronger" and that despite "[t]he project was a great opportunity [...] to apply my knowledge of [heat and mass transfer] and differential [equations], [it did feel] like two separate topics within the project itself".

\subsection{Motivation and awareness}

A key goal of the project was to bring awareness to the students about reactor safety (Question 7) and the importance of proper design of safety measures (Question $5)$. The project was very successful in bringing awareness of such critical concepts for chemical engineers with more than $84 \%$ of the students answering "agreed" or "strongly agreed" to Questions 5 and 7. For example, a student commented that "The project was a great way to incorporate safety into our learning. It definitely opened my eyes to the hazards associated with chemical engineering". More importantly, with respect to their role as professional engineers, $86 \%$ of the students agreed or strongly agreed that thanks to the project, they are more aware of their duties to report errors and malpractices when the safety of the public or their co-workers is compromised.

\subsection{Project structure and support}

Making sure to align instruction of material in class on time for the students to be able to conduct the project is fundamental. Both courses had to follow a predetermined schedule for the students to have enough time to learn the new material and apply it in the context of the project. 


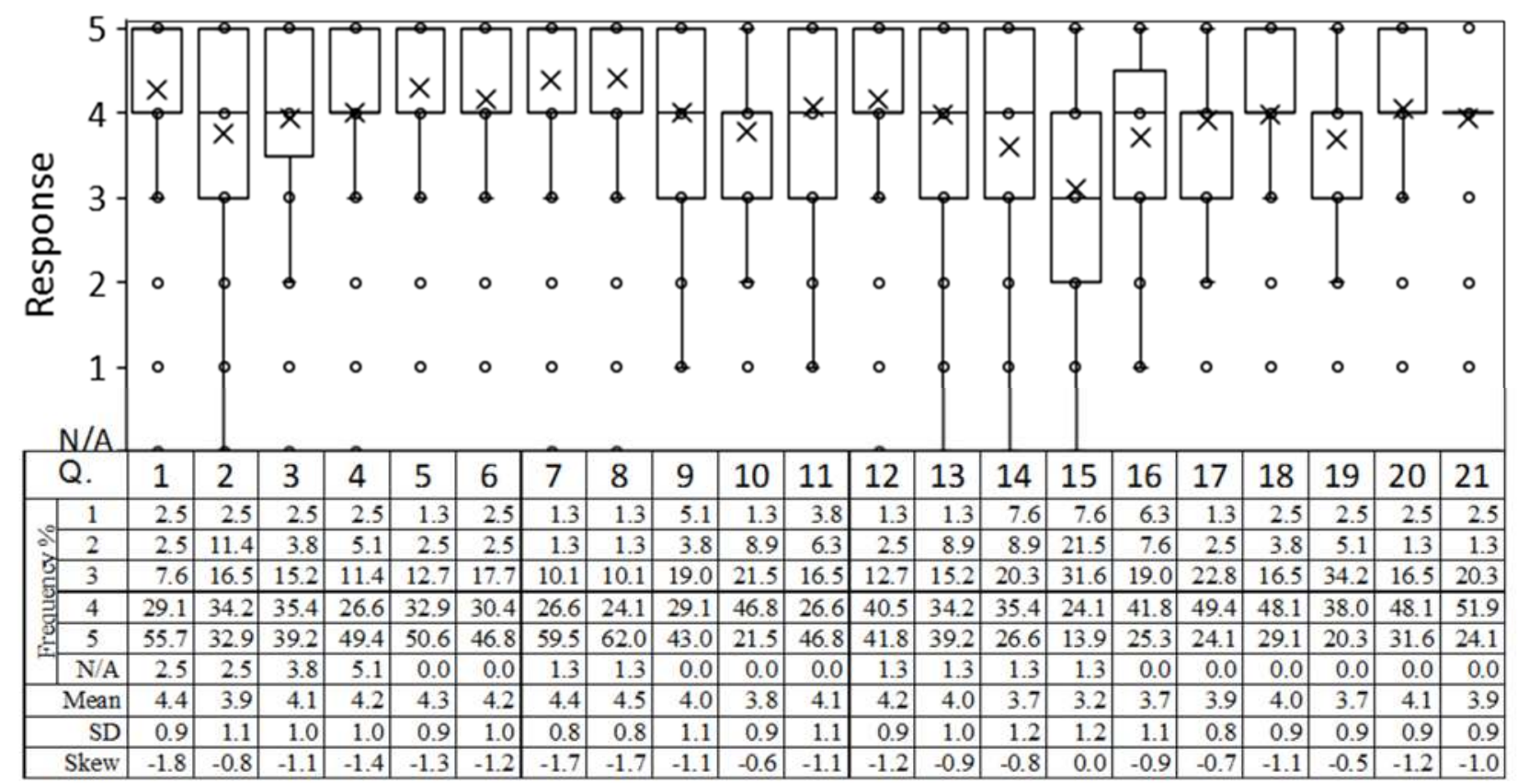

Fig 3. Survey results. Rating scale: 1=strongly disagree, $2=$ disagree, $3=$ neutral, 4=agree, and 5=strongly agree, $\mathrm{N} / \mathrm{A}=$ not applicable. On each box plot: the cross represents the average, the upper and lower limits of the box represent the $75^{\text {th }}$ and $25^{\text {th }}$ percentiles, respectively, the middle bar represents the median, the upper and lower whiskers represent the $90^{\text {th }}$ and $10^{\text {th }}$ percentiles, respectively, and the circles indicate outliers.

The students agreed or strongly agreed that the project milestones, i.e. the mid and final reports, were in line with the Heat Transfer (82\%) and Applied Differential Equations (73\%) instruction (Questions 12 and 13). Even though $73 \%$ of the students agreed or strongly agreed that the project guidance was sufficient, about a third of the class felt that the project workload was too heavy (38\%), another third disagreed or strongly disagreed $(29 \%)$, and the last third was neutral about it (32\%) (Question 15). Despite that, they considered that the time spent on the project was adequate for the assigned mark of $10 \%$ of the final grade for each course (62\% agreed or strongly agreed, Question 14).

\subsection{Personal experience and skills development}

The combined project was effective in developing analytical and critical thinking skills for the students (77\% agreed or strongly agreed, Question 18), as well as to help them take responsibility for their learning experience (73\% agreed or strongly agreed, Question 17). However, it was not seen as an effective means to develop their writing skills: only $58 \%$ of the students agreed or strongly agreed that the project helped them in this area. This was expected as most part of the project reports consisted of calculations lines, with only a few sections dedicated to commenting on the results and their role as future professional engineers. Finally, another important goal of the project was to get the students to work effectively in teams. A large proportion of the students $(80 \%)$ agreed or strongly agreed that the project allowed them to practice and develop their teamwork skills (Question 20). An important positive result of this combined project was that $76 \%$ of the students agreed or strongly agreed that the project allowed them to explain to the members of their team what they learnt and did in their assigned tasks (Question 21).

A fundamental objective of the project was to ensure that the students would communicate and work in teams effectively, instead of simply work independently on separate tasks. However, as discussed below, strategies could be implemented to further improve this aspect in future years.

\section{FINAL REMARKS: How to improve the student experience in a future combined project}

The project had a good scaffolding structure for the heat transfer part, as the different cases were building upon each other. This was meant to ensure the students were working on a complex problem with various scenarios, while having to follow clear steps from one scenario to the next one. This approach forced all students from the team to take part on each section of the project on heat transfer. As expected, some students would have preferred not to have to do the whole work, as seen with the comment below:

"It was difficult working on the team because some sections had to be done with the work from previous 
sections, but only those who did those sections had an understanding of how they worked. Thus, all members had to do ALL the work to understand the project and so it was inefficient and too much work to handle."

However, one of our objectives was for every student to conduct the work. To avoid such resistance in future years, it is recommended to make it clearer earlier in the semester that it is expected that all students work together on all the parts of the project.

Even though $75 \%$ of the students agreed or strongly agreed that the project allowed them to relate the concepts from both courses (Question 3), the integration of both courses could be further improved, as noted from some of the student comments listed above. Indeed, a few students admitted that one of their group members was exclusively working on the ODE coding part of the project:

"I feel like it should be more inclusive in terms of the material. For example, I only did the parts of the project that involved MATLAB and the rest of my team carried out the physics part. I wish I had been more involved in that part but it seemed like the way we did it was the most effective way."

However, a student recognized that it was his/her own choice not to be involved in some parts of the project:

"I sadly didn't get an opportunity to improve my heat and mass skills very much, because other group members worked on those sections (That was my fault, not the projects)."

It should be noted that these comments should not be considered as representative of the whole class as $76 \%$ of the students agreed or strongly agreed that the project allowed them to practice their MATLAB coding skills (Question 4). Therefore, a large majority of the students was involved in all parts of the project.

To summarize, it is clear that some students never did some parts of the project, i.e., they did not learn from all parts of the project as the instructors had wished. However, with the way they split the tasks, they were able to identify each other's strengths and expertise, therefore working efficiently as a team towards the objective of completing the project. This is a positive outcome of the project, as two of the learning objectives were to "identify the preferred style of teammates and describe how these styles contribute to a team" and to "identify and apply tools and techniques to make an engineering team more effective" (Table 1). These comments helped understand that a few incentives should be implemented to encourage the students to take part in both the heat transfer and applied differential equations aspects of the project. For example, the students could be encouraged to answer at least one of the five cases in the MATLAB coding component of the project to ensure that one individual is not responsible for the MATLAB component.

Some students who felt that the project was challenging seemed to not have implemented an effective team strategy to share information: "Some questions in the report were tough and should have been explained in class time rather than the additional tutorial because some people cannot stay after class time". Not all students from the teams needed to participate in all extra tutorials provided. Helping the students get organized on how to share such tasks of gathering information from the instructors is an aspect that can be improved in the future.

Finally, as students' answers to Question 10 with respect to the clarity of the learning objectives of the project were more diverse, it would be worth rewording them for future iterations of the project, in particular to make it clearer that all students are expected to take part in all aspects of the project.

\section{Acknowledgements}

The authors gratefully appreciate the participation of the students in the survey. The authors also acknowledge the guidance to the students provided by Albert Huynh from the iLead team at the University of Toronto, on teamwork skills during the project tutorials.

\section{References}

[1] CSB. Hazard investigation. Improving reactive hazard management. USA: US Chemical Safety and Hazard Investigation Board, October 2002, pp. 150. \{Report No. 200101-H\} Available as of May 1 ${ }^{\text {st }}, 2017$ from

http://www.csb.gov/improving-reactive-hazard-management/ [2] G. Drogaris. Review of accidents involving unexpected/runaway reactions. Brussels, Luxemburg: Commission of the European Communities, 2010, 60pp. \{ISBN: 92-826-4736-6\} Available as of May 1st, 2017 from

https://bookshop.europa.eu/en/community-documentationcentre-on-industrial-risk-pbCLNA14634/

[3] PEO. Professional Engineers Act: R.R.O. 1990, Regulation 941 General. Professional Engineers of Ontario, 2015, 28 pp.

Available as of May 1st, 2017 from

https://www.ontario.ca/laws/regulation/900941

[4] R.J. Willey, H.S. Fogler and M.B. Cutlip "The integration of process safety into a chemical reaction engineering course: Kinetic modeling of the T2 incident". Process Safety Progress, vol. 30, no. 1, pp. 39-44, 2011. doi:10.1002/prs.10431.

[5] Martin J. Pitt. Teaching Safety in Chemical Engineering: What, How and Who? Chem. Eng. Technol., vol. 35, no. 8, pp. 1341-1345, 2012. doi: 10.1002/ceat.201200024.

[6] Anton Pintar. "Teaching chemical process safety: A separate course versus integration into existing courses".in Proc. ASEE Annual Conference (Charlotte, NC: 20-23 June), 10 pp.,2011. Available as of May 1st, 2017 from https://peer.asee.org/7963 [7] John W. Thomas. A review of research on project-based learning. The Autodesk Foundation, March 2000.

Available as of May 1st, 2017 from http://www.bobpearlman.org/BestPractices/PBL Research.pdf [8] Clive Ferguson and Stuart Palmer. "An evaluation of the impact of using authentic design and build industry projects in project-based learning". in Proc. AAEE2014 Conference,

A. Bainbridge-Smith, ZT. Qi, GS. Gupta, (eds.) (Wellington, New Zealand: 8-10 December), 9 pp., 2014. 
[9] Marcelo A.C. Fernandes. Project-Based Learning Laboratory for Teaching Embedded Systems. Mathematical Problems in Engineering, vol. 2015, Article ID 236749, 8 pp. 2015. doi:10.1155/2015/236749.

[10] Jacek Uziak. "A project-based learning approach in an engineering curriculum". Global Journal of Engineering Education, vol. 18, no. 2, pp. 119-123, 2016.

[11] Bill Elmore. "Conducting Project-based learning with a large chemical engineering freshman cohort using LEGO NXT robotics". in Proc. AAEE2014 Conference, A. BainbridgeSmith, ZT. Qi, GS. Gupta, (eds.) (Wellington, New Zealand: 810 December), 13 pp., 2014.

[12] Bernadette Foley and Craig Willis. "Transforming engineering students into student engineers through multi-course project-based learning". in Proc. AAEE2014 Conference,

A. Bainbridge-Smith, ZT. Qi, GS. Gupta, (eds.) (Wellington, New Zealand: 8-10 December), 8 pp., 2014.
[13] CSB. Investigation report. T2 Laboratories, Inc. Runaway reaction. USA: US Chemical Safety and Hazard Investigation Board, September 2009, pp. 150. \{Report No. 2008-3-I-FL\}

[14] Theodore L. Bergman, Adrienne S. Lavine, Frank P. Incropera and David P. Dewitt. Fundamentals of Heat and Mass Transfer. Hoboken, NJ: John Wiley \& Sons, (7th ed.), 1076 pp. \{ISBN: 978-0470-50197-9\}

[15] PEO. A professional engineer's duty to report. Professional Engineers of Ontario, 2015, 2 pp.

Available as of May 1st, 2017 from

http://www.peo.on.ca/index.php/ci_id/16158/la_id/1.htm

\section{APPENDIX: SURVEY QUESTIONAIRIE}

\begin{tabular}{|l|l|}
\hline \multicolumn{3}{|c|}{ A.- Contribution to learning } \\
\hline $\mathbf{1 .}$ & The project allowed me to practice the Heat Transfer concepts covered in CHE210 lectures. \\
\hline $\mathbf{2 .}$ & The project allowed me to practice the Applied Differential Equations concepts covered in CHE222 lectures. \\
\hline $\mathbf{3 .}$ & The project allowed me to relate the concepts of Heat Transfer and Applied Differential Equations. \\
\hline 4. & The project allowed me to practice the MATLAB coding skills acquired in CHE222 lectures and labs. \\
\hline
\end{tabular}

\begin{tabular}{|l|l|}
\hline \multicolumn{2}{|l|}{ B.- Motivation and awareness } \\
\hline $\mathbf{5 .}$ & $\begin{array}{l}\text { The project helped me to explain the importance of cooling system and pressure relief system designs and the } \\
\text { possible consequences of poor design and failure of these systems. }\end{array}$ \\
\hline $\mathbf{6 .}$ & $\begin{array}{l}\text { The project helped me to recognize that assumptions are a fundamental part of the design and problem- } \\
\text { solving processes. }\end{array}$ \\
\hline $\mathbf{7 .}$ & $\begin{array}{l}\text { As a result of the project I am more aware that exothermic reactions are a potential safety hazard in the } \\
\text { chemical industry. }\end{array}$ \\
\hline $\mathbf{8 .}$ & $\begin{array}{l}\text { As a result of the project I am more aware of my duties as an engineer to ensure the safety of the public and } \\
\text { coworkers and to report errors and malpractices. }\end{array}$ \\
\hline $\mathbf{9 .}$ & The project motivated me to further learn about reactor safety. \\
\hline
\end{tabular}

\begin{tabular}{|l|l|}
\hline \multicolumn{2}{|c|}{ C.- Project structure and support } \\
\hline $\mathbf{1 0 .}$ & The Learning Objectives of the project were clear and I was able to achieve them. \\
\hline $\mathbf{1 1 .}$ & The project Teaching Assistant's guidance was sufficient to complete the project. \\
\hline $\mathbf{1 2 .}$ & The two project report submissions (mid and final) were in line with the CHE210 material covered. \\
\hline $\mathbf{1 3 .}$ & The two project report submissions (mid and final) were in line with the CHE222 material covered. \\
\hline $\mathbf{1 4 .}$ & The time spent on the project is adequate to the assigned mark for each course. \\
\hline $\mathbf{1 5 .}$ & The workload was too heavy compared to the benefit I got from doing the project. \\
\hline
\end{tabular}

\begin{tabular}{|l|l|}
\hline \multicolumn{2}{|c|}{ D.- Personal experience and skills development } \\
\hline $\mathbf{1 6 .}$ & I enjoyed the project. \\
\hline $\mathbf{1 7 .}$ & The project allowed me to take responsibility of my learning experience. \\
\hline $\mathbf{1 8 .}$ & The project allowed me to practice my analysis and critical thinking skills. \\
\hline $\mathbf{1 9}$. & The project allowed me to practice my report writing skills. \\
\hline $\mathbf{2 0 .}$ & The project allowed me to practice and develop my teamwork skills. \\
\hline $\mathbf{2 1 .}$ & $\begin{array}{l}\text { The project allowed me to explain to my teammates my experience and what I learned from the tasks I } \\
\text { carried out. }\end{array}$ \\
\hline
\end{tabular}

\begin{tabular}{|l|l|}
\hline \multicolumn{2}{|c|}{ E.- Open comments section (Optional) } \\
\hline 22. & Please provide any additional comments regarding your experience with the project \\
\hline
\end{tabular}

